Old Dominion University

ODU Digital Commons

Engineering Management \& Systems

Engineering Management \& Systems

Engineering Faculty Publications

Engineering

2019

\title{
Framework For Improving Complex System Performance
}

Charles B. Keating

Old Dominion University

Polinpapilinho F. Katina

Ra'ed Jaradat

Joseph M. Bradley

Richard Hodge

Follow this and additional works at: https://digitalcommons.odu.edu/emse_fac_pubs

Part of the Systems Engineering Commons

Original Publication Citation

Keating, C. B., Katina, P. F., Jaradat, R., Bradley, J. M., \& Hodge, R. (2019). Framework for improving complex system performance. INCOSE International Symposium, 29(1), 1218-1232. https://doi.org/ 10.1002/j.2334-5837.2019.00664.x

This Conference Paper is brought to you for free and open access by the Engineering Management \& Systems Engineering at ODU Digital Commons. It has been accepted for inclusion in Engineering Management \& Systems Engineering Faculty Publications by an authorized administrator of ODU Digital Commons. For more information, please contact digitalcommons@odu.edu. 


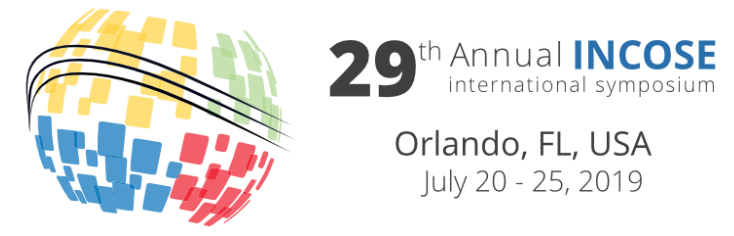

\title{
Framework for Improving Complex System Performance
}

\author{
Charles B. Keating \\ Old Dominion University, Norfolk Virginia \\ ckeating@odu.edu
}

\author{
Polinpapilinho F. Katina \\ University of South Carolina Upstate \\ Spartanburg, South Carolina \\ pkatina@uscupstate.edu
}

Joseph M. Bradley

Old Dominion University, Norfolk Virginia

josephbradley@leading-change.org

\author{
Ra'ed Jaradat \\ Mississippi St. University \\ Starksville Mississippi \\ jaradat@ise.msstate.edu
}

\author{
Richard Hodge \\ Brooke Global, Melbourne, VIC \\ richardhodge@brooke.global
}

Copyright $\odot 2019$ by Charles B. Keating, Polinpapilinho F. Katina, Ra’ed Jaradat, Joseph M. Bradley, Richard Hodge. Published and used by INCOSE with permission.

\begin{abstract}
This paper introduces a framework for improvement of complex system performance. Complex systems are besieged with conditions marked by increasing uncertainty, emergence, and ambiguity. Additionally, demands for increased productivity, resource efficiencies, and performance improvement make new approaches paramount for modern systems engineers. In response, a framework to improve complex system performance is developed. Following an introduction, the paper pursues four objectives: (1) introduction of Complex System Governance (CSG) as a foundation to describe essential system functions, (2) suggest system 'pathologies' as an explanation for deep system performance issues, (3) exploration of system performance improvement as a function of 'requisite variety' to compensate for deep system issues, and (4) introduce a framework for complex system performance improvement using system pathologies as 'unabsorbed variety'. The paper closes with some challenges for further development of the framework for deployment and application guidance for practitioners.
\end{abstract}

\section{Introduction}

Practitioners continue to be besieged with complex systems and their problems that at first glance appear increasingly intractable. The shifting landscape of the systems engineering practitioner might be characterized by several dominant characteristics. Following previous recitations of this landscape from recent works (Jaradat \& Keating, 2014; Keating, Katina, \& Bradley, 2015; Keating, 2014; Keating \& Katina, 2011; Keating, et al. 2018), the following summary is offered with respect to characteristics and their nature for the domain faced by system practitioners dealing with complex systems (Table 1).

Table 1: Domain of Systems Practitioners 


\begin{tabular}{|c|c|}
\hline Characteristics & Nature \\
\hline Complexity & $\begin{array}{l}\text { - Exponential magnitude, availability, and accessibility of information cou- } \\
\text { pled with the increasingly large number of richly interconnected elements. } \\
\text { - Incomplete, fallible, and dynamically evolving system knowledge. } \\
\text { - High levels of uncertainty beyond current capabilities to structure, order, } \\
\text { and reasonably couple decisions, actions, and consequences. } \\
\text { - Emergence of behavior, performance, and consequences that cannot be } \\
\text { known or predicted in advance of their occurrence. }\end{array}$ \\
\hline $\begin{array}{l}\text { Contextual } \\
\text { Dominance }\end{array}$ & $\begin{array}{l}\text { - Unique circumstances, factors, patterns, and conditions within which a } \\
\text { system is embedded - influencing the system and influenced by the system. } \\
\text { - Enabling and constraining to decisions, actions, and interpretations made } \\
\text { with respect to the system. } \\
\text { - Multiple stakeholders with different worldviews, objectives, and influence } \\
\text { patterns. }\end{array}$ \\
\hline Ambiguity & $\begin{array}{l}\text { - Instabilities in understanding system structure, behavior, or performance. } \\
\text { - Potential lack of clarity in system identity, boundary conditions, delineation } \\
\text { of system constituents, and understanding of a system and its context. }\end{array}$ \\
\hline Holistic Nature & $\begin{array}{l}\text { - In addition to technical/technology aspects of a system, consideration for the } \\
\text { entire influencing spectrum of human/social, organizational/managerial, } \\
\text { policy, political, and information aspects central to a more complete (holis- } \\
\text { tic) view of a system. } \\
\text { - Behavior and performance as a function of interactions in the system - not } \\
\text { reducible or revealed by understanding individual constituents. }\end{array}$ \\
\hline
\end{tabular}

This set of circumstances seems to present a somewhat bleak future for systems practitioners tasked with improving system performance with increasingly scarce resources and extended demands for efficiency. In response, this paper develops a framework that serves to provide better understanding of systemic deficiencies and potential for improving complex system performance. The remainder of the paper is organized to accomplish four primary objectives:

1. Provide an overview of Complex System Governance as a systems based approach to dealing with the problem domain specified above.

2. Introduce the concept of system 'pathologies' as a systems theory based explanation of deep system performance issues,

3. Explore system performance improvement as a function of establishing 'requisite variety' to compensate for deep system issues in design, execution, or development for a complex system,

4. Introduce a first generation framework and application guidance for improvement of complex system performance through the rigorous examination of systems pathologies and responsive strategies. 


\section{Complex System Governance}

The problems emanating from this domain appear to be intractable. In any cursory look at the present state of complex systems and their problems it is easily concluded that we have not, and are not, mounting an effective response. Given the current level of ineffectiveness in dealing with complex system problems that have proliferated into all aspects of human endeavor, CSG has been introduced. It is in the domain presented above that CSG is being postured to impact practitioner capabilities to more effectively address growing concerns. CSG is primarily based in Systems Theory (Skyttner, 2005; von Bertlanffy, 1956, 1968; Adams, et al., 2014) and Management Cybernetics (Beer, 1979, 1981, 1985) and has been built upon their philosophical, theoretical, and methodological underpinnings. At this point in our development, we introduce CSG as it has been previously defined as the design, execution, and evolution of the metasystem functions necessary to provide control, communication, coordination, and integration of a complex system (Keating, et al., 2014).

In many cases our systems have developed over time through processes of accretion or self-organization. Accretion is a process whereby elements are added in a piecemeal fashion until the whole system appears fragmented and no longer makes sense. Self-organization involves letting system structure and resulting behavior develop with minimal design oversight. This can produce results that may or may not be consistent with expectations or desirable performance. The result of either of these system development processes, accretion or self-organization, can and often do result in systems that fail to meet performance expectations. In effect, development is not purposeful, resulting in a condition we refer to as 'system drift'. Just as a powerless ship drifts along its intended course subject to uncontrollable currents, so too can our systems experience drift resulting from development by accretion or self-organization. System drift symbolizes a system that is subject to the unintended consequences that accrue in the absence of a purposefully executed design. In the end, system drift describes a condition all too familiar to practitioners who must navigate systems through the increasingly complex environment, while confronting seemingly intractable issues on a daily basis. CSG is a coherent response to system drift.

CSG is one of many systems based approaches designed to better deal with complexity and what we referred to earlier as 'system drift'. System drift denotes systems that, irrespective of the noblest intentions, have either never been properly designed or whose execution continually fails to meet desired performance expectations. In short, these 'drifting' systems fall short of delivering minimal value expected, much less producing high performance. We do not need to look far to see examples of drifting systems. In fact, it would be a rare day that we would not be impacted by systems in drift. Consider the following examples: (1) launching of a new Enterprise Resource Planning initiative that collapses due to emergent incompatibilities with existing systems, (2) a costly crisis from discovery of noncompliance to a regulatory requirement that has been in existence for several years but never identified, or (3) introduction of a new purchasing policy that achieves intended reductions in supplier costs but increases overall costs due to resulting schedule delays. Unfortunately, the impacts of system drift are not limited to increased costs. These drifting systems have considerable associated human cost. These human costs are borne by those that must suffer through these drifting systems by compensating for their ineffectiveness. CSG supports thinking, decision, and action to proactively and purposefully address system drift. Ultimately, CSG is intended to reduce the high human costs characteristic of these systems in drift.

Systems-based approaches, such as CSG, and the systems thinking upon which they are founded, are certainly not 'new' in trying to address what we described as system drift. In fact, the foun- 
dations of systems thinking have been traced as far back as the ancient Chinese work The I Ching (translated as Book of Change dated prior to 400 B.C.) that noted the dynamic nature of changing relationships among elements. Additionally, the central philosophical tenet of systems thinking, holism, can be traced back to the writings of Aristotle, who suggested that 'the whole is more than the sum of its parts'. Thus, approaches based in systems thinking and 'holism' are not new and have historically represented a significant step toward dealing with system drift. However, what is new in bringing CSG applied research to the problem domain is the fusion of Systems Theory and Management Cybernetics to provide practitioners with perspective, supporting methods, and tools to confront drifting systems. This practitioner focused CSG research seeks to increase capabilities for better understanding, decision, and action in dealing with complex systems and their associated problems. In essence, CSG seeks to increase effectiveness in dealing with system drift.

CSG is focused on providing practitioners with perspective, methods, and tools to better understand and deal with complexities they must routinely confront. In essence, CSG helps avoid system drift through purposeful design, similar to a ship changing heading or speed to compensate for the effects of wind or current. The ability to effectively respond to these realities will separate the high performance systems from the 'also ran' systems in the future. We might hope that this situation would only be a temporary aberration from normal. Unfortunately, these conditions are not likely to subside in the near or distant future. Instead they are more likely to intensify. Practitioners responsible for systems must adjust to thrive in this 'new normal' reality. Those who do not shift the level of decision, action, and understanding in response, in the best case scenario will likely experience system drift firsthand. In the worst case scenario, they are likely to experience outright failure.

For succinctness, Table 1, drawn from the work of Katina (2016) presents a summary of the nine essential metasystem functions of a complex system. The 'metasystem' acts to provide governance (design, oversight, accountability) of a complex system (following Keating and Bradley, 2015; Keating et al., 2017) through:

- Control - constraints necessary to ensure consistent performance and future system trajectory

- Communications - flow and processing of information necessary to support consistent decision, action, and interpretation throughout the system

- Coordination - providing for effective interaction to prevent unnecessary instabilities within and in relationship to entities external to the system

- Integration - maintaining system unity through common goals, designed accountability, and maintaining balance between system and constituent interests

Table 1. Metasystem functions for a complex system

\begin{tabular}{|c|c|}
\hline Metasystem function & Primary role of the function \\
\hline $\begin{array}{l}\text { Metasystem five (M5): } \\
\text { Policy and identity }\end{array}$ & $\begin{array}{l}\text { To provide direction, oversight, accountability, and evolution of the } \\
\text { System. Focus includes policy, mission, vision, strategic direction, } \\
\text { performance, and accountability for the system such that: (1) the } \\
\text { system maintains viability, (2) identity is preserved, and (3) the } \\
\text { system is effectively projected both internally and externally. }\end{array}$ \\
\hline Metasystem Five Star & $\begin{array}{l}\text { To monitor the system context (i.e., the circumstances, factors, } \\
\text { conditions, or patterns that enable and constrain the system). }\end{array}$ \\
\hline
\end{tabular}




\begin{tabular}{|c|c|}
\hline$\left(M 5^{*}\right):$ System context & \\
\hline $\begin{array}{l}\text { Metasystem Five Prime } \\
(\text { M5'): Strategic system } \\
\text { monitoring }\end{array}$ & $\begin{array}{l}\text { To monitor measures for strategic system performance and identify } \\
\text { variance requiring metasystem level response. Particular emphasis } \\
\text { is on variability that may impact future system viability. Maintains } \\
\text { system context. }\end{array}$ \\
\hline $\begin{array}{l}\text { Metasystem Four (M4): } \\
\text { System development }\end{array}$ & $\begin{array}{l}\text { To provide for the analysis and interpretation of the implications and } \\
\text { potential impacts of trends, patterns, and precipitating events in the } \\
\text { environment. Develops future scenarios, design alternatives, and } \\
\text { future focused planning to position the System for future viability. }\end{array}$ \\
\hline $\begin{array}{l}\text { Metasystem Four Star } \\
\left(M 4^{*}\right): \text { Learning and } \\
\text { transformation }\end{array}$ & $\begin{array}{l}\text { To provide for identification and analysis of metasystem design } \\
\text { errors (second order learning) and suggest design modifications and } \\
\text { transformation planning for the System. }\end{array}$ \\
\hline $\begin{array}{l}\text { Metasystem Four Prime } \\
\left(\text { M4' }^{\prime}\right): \text { Environmental } \\
\text { scanning }\end{array}$ & $\begin{array}{l}\text { To provide the design and execution of scanning for the system } \\
\text { environment. Focus is on patterns, trends, threats, events, and op- } \\
\text { portunities for the system }\end{array}$ \\
\hline $\begin{array}{l}\text { Metasystem Three (M3): } \\
\text { System operations }\end{array}$ & $\begin{array}{l}\text { To maintain operational performance control through the imple- } \\
\text { mentation of policy, resource allocation, and design for accounta- } \\
\text { bility. }\end{array}$ \\
\hline $\begin{array}{l}\text { Metasystem Three Star } \\
\left(M 3^{*}\right): \text { Operational per- } \\
\text { formance }\end{array}$ & $\begin{array}{l}\text { To monitor measures for operational performance and identify } \\
\text { variance in system performance requiring system level response. } \\
\text { Particular emphasis is on variability and performance trends that } \\
\text { may impact system viability. }\end{array}$ \\
\hline $\begin{array}{l}\text { Metasystem Two (M2): } \\
\text { Information and commu- } \\
\text { nications }\end{array}$ & $\begin{array}{l}\text { To enable system stability by designing and implementing archi- } \\
\text { tecture for information flow, coordination, transduction and com- } \\
\text { munications within and between the metasystem, the environment, } \\
\text { and the systems being governed. }\end{array}$ \\
\hline
\end{tabular}

\section{System Pathologies}

Complex System Governance (CSG) provides a set of 'coordinates' to locate the existence of a pathology. This location is identified to nine different functions essential to continued viability of a complex system. Certainly, understanding of system performance involves discovery of conditions that might act to limit that performance. Previous research related to systems theory and systems theory-based methodologies offers insights that provide explanation for aberrant conditions affecting performance (Keating and Katina, 2012). These aberrant conditions have been labeled as pathologies, defined as, "A circumstance, condition, factor, or pattern that acts to limit system performance, or lessen system viability <existence>, such that the likelihood of a system achieving performance expectations is reduced." (Keating and Katina, 2012, p. 214). Pathologies have a rich development and have been anchored in Systems Theory (the set of laws and principles that govern behavior of all complex systems) and Management Cybernetics (the science of system structural organization).

For grounding our present exploration, we introduce two key points related to the nature and role of pathologies in complex systems - pathologies and their relationship to Systems Theory. First, 
pathologies have been extensively developed for application to the design, execution and development (governance) of complex systems (Keating and Katina, 2012; Katina, 2015).

Given this brief introduction to pathologies in complex systems, following the recent work of Katina (2016) and earlier work of Keating and Katina (2012) a set of 53 pathologies have been develop in relationship to the metasystem functions provided earlier (Table 2). These pathologies are organized around the nine metasystem functions and serve to identify aberrations to normal (healthy) functioning of a complex system (e.g. acquisition).

Table 2. Pathologies corresponding to metasystem functions

\begin{tabular}{|c|c|}
\hline Metasystem function & Corresponding set of pathologies \\
\hline \multirow{6}{*}{$\begin{array}{l}\text { Metasystem five } \\
\text { (M5): Policy and } \\
\text { identity }\end{array}$} & $\begin{array}{l}\text { M5.1. Identity of system is ambiguous and does not effectively generate consistency system } \\
\text { decision, action, and interpretation. }\end{array}$ \\
\hline & $\begin{array}{l}\text { M5.2. System vision, purpose, mission, or values remain unarticulated, or articulated but not } \\
\text { embedded in the execution of the system. }\end{array}$ \\
\hline & $\begin{array}{l}\text { M5.3. Balance between short term operational focus and long term strategic focus is unex- } \\
\text { plored. }\end{array}$ \\
\hline & M5.4. Strategic focus lacks sufficient clarity to direct consistent system development. \\
\hline & $\begin{array}{l}\text { M5.5. System identity is not routinely assessed, maintained, or questioned for continuing } \\
\text { ability to guide consistency in system decision and action. }\end{array}$ \\
\hline & M5.6. External system projection is not effectively performed. \\
\hline \multirow{3}{*}{$\begin{array}{l}\text { Metasystem Five Star } \\
(M 5 *) \text { : System con- } \\
\text { text }\end{array}$} & M5*.1. Incompatible metasystem context constraining system performance. \\
\hline & M5*.2. Lack of articulation and representation of metasystem context. \\
\hline & M5*.3. Lack of consideration of context in metasystem decisions and actions. \\
\hline \multirow{3}{*}{$\begin{array}{l}\text { Metasystem Five } \\
\text { Prime (M5'): Strate- } \\
\text { gic system monitoring }\end{array}$} & M5'.1. Lack of strategic system monitoring. \\
\hline & M5'.2. Inadequate processing of strategic monitoring results. \\
\hline & M5'.3. Lack of strategic system performance indicators. \\
\hline \multirow{5}{*}{$\begin{array}{l}\text { Metasystem Four } \\
\text { (M4): System devel- } \\
\text { opment }\end{array}$} & M4.1. Lack of forums to foster system development and transformation. \\
\hline & $\begin{array}{l}\text { M4.2. Inadequate interpretation and processing of results of environmental scanning - } \\
\text { non-existent, sporadic, limited. }\end{array}$ \\
\hline & M4.3. Ineffective processing and dissemination of environmental scanning results. \\
\hline & $\begin{array}{l}\text { M4.4. Long-range strategic development is sacrificed for management of day-to-day oper- } \\
\text { ations - limited time devoted to strategic analysis. }\end{array}$ \\
\hline & M4.5. Strategic planning/thinking focuses on operational level planning and improvement. \\
\hline \multirow{4}{*}{$\begin{array}{l}\text { Metasystem Four } \\
\text { Star }(M 4 *) \text { : Learning } \\
\text { and transformation }\end{array}$} & M4*.1. Limited learning achieved related to environmental shifts. \\
\hline & M4*.2. Integrated strategic transformation not conducted, limited, or ineffective. \\
\hline & M4*.3. Lack of design for system learning - informal, non-existent, or ineffective. \\
\hline & M4*.4. Absence of system representative models - present and future. \\
\hline \multirow{5}{*}{$\begin{array}{l}\text { Metasystem Four } \\
\text { Prime (M4'): Envi- } \\
\text { ronmental scanning }\end{array}$} & M4'.1. Lack of effective scanning mechanisms. \\
\hline & M4'.2. Inappropriate targeting/undirected environmental scanning. \\
\hline & M4'.3. Scanning frequency not appropriate for rate of environmental shifts. \\
\hline & M4'.4. System lacks enough control over variety generated by the environment. \\
\hline & M4'.5. Lack of current model of system environment. \\
\hline \multirow{3}{*}{$\begin{array}{l}\text { Metasystem Three } \\
\text { (M3): System opera- } \\
\text { tions }\end{array}$} & $\begin{array}{l}\text { M3.1. Imbalance between autonomy of productive elements and integration of whole sys- } \\
\text { tem. }\end{array}$ \\
\hline & $\begin{array}{l}\text { M3.2. Shifts in resources without corresponding shifts in accountability/shifts in accounta- } \\
\text { bility without corresponding shifts in resources. }\end{array}$ \\
\hline & M3.3. Mismatch between resource and productivity expectations. \\
\hline
\end{tabular}




\begin{tabular}{|c|c|}
\hline & clarity for responsibility, expectations, and accountability for performance. \\
\hline & M3.5. Operational planning frequently pre-empted by emergent crises. \\
\hline & M3.6. Inappropriate balance between short term operational versus long term strategic focus. \\
\hline & M3.7. Lack of clarity of operational direction for productive entities (i.e., subsystems). \\
\hline & M3.8. Difficulty in managing integration of system productive entities (i.e., subsystems). \\
\hline & M3.9. Slow to anticipate, identify, and respond to environmental shifts. \\
\hline & M3*.1. Limited accessibility to data necessary to monitor performance. \\
\hline & M3*.2. System-level operational performance indicators are absent, limited, or ineffective. \\
\hline & M3*.3. Absence of monitoring for system and subsystem level performance. \\
\hline Metasystem Three & $\begin{array}{l}\text { M3*.4. Lack of analysis for performance variability or emergent deviations from expected } \\
\text { performance levels - the meaning of deviations. }\end{array}$ \\
\hline $\begin{array}{l}\text { Star }(M 3) \text { : Opera- } \\
\text { tional performance }\end{array}$ & $\begin{array}{l}\text { M3*.5. Performance auditing is non-existent, limited in nature, or restricted mainly to } \\
\text { troubleshooting emergent issues. }\end{array}$ \\
\hline & $\begin{array}{l}\text { M3*.6. Periodic examination of system performance largely unorganized and informal in } \\
\text { nature. }\end{array}$ \\
\hline & M3*.7. Limited system learning based on performance assessments. \\
\hline & M2.1. Unresolved coordination issues within the system. \\
\hline & $\begin{array}{l}\text { M2.2. Excess redundancies in system resulting in inconsistency and inefficient utilization of } \\
\text { resources - including information. }\end{array}$ \\
\hline & M2.3. System integration issues stemming from excessive entity isolation or fragmentation. \\
\hline & M2.4. System conflict stemming from unilateral decisions and actions. \\
\hline & $\begin{array}{l}\text { M2.5. Excessive level of emergent crises - associated with information transmission, } \\
\text { communication, and coordination within the system. }\end{array}$ \\
\hline $\begin{array}{l}\text { Metasystem Two } \\
\text { (M2): Information }\end{array}$ & $\begin{array}{l}\text { M2.6. Weak or ineffective communications systems among system entities (i.e., subsys- } \\
\text { tems). }\end{array}$ \\
\hline and communications & $\begin{array}{l}\text { M2.7. Lack of standardized methods (i.e., procedures, tools, and techniques) for routine } \\
\text { system level activities. }\end{array}$ \\
\hline & $\begin{array}{l}\text { M2.8. Overutilization of standardized methods (i.e., procedures, tools, and techniques) } \\
\text { where they should be customized. }\end{array}$ \\
\hline & M2.9. Overly ad-hoc system coordination versus purposeful design. \\
\hline & $\begin{array}{l}\text { M2.10. Difficulty in accomplishing cross-system functions requiring integration or stand- } \\
\text { ardization. }\end{array}$ \\
\hline & M2.11. Introduction of uncoordinated system changes resulting in excessive oscillation. \\
\hline
\end{tabular}

A second essential and fundamental grounding for development of pathologies is their linkage to Systems Theory based laws/principles. For our present purposes, the nature of pathologies in complex systems can be captured in the following critical points and their suggested relevance to system practitioners and system development:

1. All systems are subject to the laws of systems. Just as there are laws governing the nature of matter and energy (e.g. physics law of gravity), so too are our systems subject to laws. These system laws are always there, always on, non-negotiable, non-biased, and explain system performance. System practitioners must ask, 'do we understand systems laws and their impact on our system(s) design and performance?'.

2. All systems perform essential system functions that determine system performance. These functions are performed by all systems, regardless of sector, size, or purpose. These functions define 'what' must be achieved for maintaining viability of a system. Every system invokes a set of unique implementing mechanisms (means of achieving system functions) that determine 'how' system functions are accomplished. Mechanisms can be formal-informal, tacit-explicit, routine-sporadic, or limited-comprehensive in nature. These functions serve to produce sys- 
tem performance which is a function of previously discussed communication, control, integration, and coordination. System practitioners must ask, 'do we understand how our system performs essential system functions to produce performance and maintain viability?

3. Violations of systems laws/principles in design, execution, or development of a system are 'pathologies' and carry consequences. Irrespective of noble intentions, ignorance, or willful disregard, violation of system laws generates pathologies and carries real consequences for system performance. In the best case, violations degrade performance. In the worst case, violations can escalate to cause catastrophic consequences or even eventual system collapse. System practitioners must ask, 'do we understand problematic system performance in terms of violations of fundamental system laws?'

4. System performance can be enhanced through development of essential system functions. When system performance fails to meet expectations, deficiencies in governance functions can offer novel insights into the deeper sources of failure. Performance issues can be traced to governance function issues as well as violations of underlying system laws. Thus, system development can proceed in a more informed and purposeful mode. Acquisition practitioners must ask, 'how might the roots of problematic performance be found in deeper system issues and violations of system laws, suggesting different development directions?'.

\section{System Performance: A Requisite Variety Perspective}

Requisite Variety was developed by Ashby (1956) to explain that a system must have sufficient regulatory capacity to match or exceed the variety being generated by the environment. Other statements of variety include: (1) the number of different states of a system (Beer, 1979), (2) "if a system is to be stable the number of states of its control mechanism must be greater than or equal to the number of states in the system being controlled (Ashby, 1956, p. 10). Lacking this variety match would result in a system not being able to effectively respond to perturbations stemming from external turbulence or internal flux. Thus, we suggest the following perspective of system performance in relationship to variety:

The regulatory capacity of a system is responsible for system performance and is a function of the interaction of system design, execution of that design, and system development (redesign). Inadequacies in system design, execution, or development produce pathologies that degrade system performance.

The key elements of this stipulation include:

1. Regulatory Capacity - this involves the capacity of the system to provide sufficient constraint such that performance is maintained. Regulatory capacity is not static and may be invoked by Accretion (adding piecemeal ad hoc elements to constrain a system), Self-Organizing (permitting the structural patterns of the system to 'take their own course' without invoking external design constraint, or Purposeful (actively engaging in the design of the system structure to embrace inevitable emergence in the environment.

2. System Design - the structure of a system that provides the ability to respond to external perturbations and internal flux. This provides resilience (ability to absorb variety and reestablish performance parameters following external disturbances), robustness (the range over which a system can be resilient, fragility (the degree to which a system is vulnerable to external fluc- 
tuation and at risk of performance degradation or collapse. System design generates a capacity to absorb variety being generated external/internal to a system. The degree to which a system design is not capable of absorbing variety presents the system with residual, or 'unabsorbed' variety. Residual variety: (1) creates a level of uncertainty in a system, (2) results in pathologies stemming from inadequacies in the system design capability to 'absorb' variety through regulatory capacity, and (3) unresolved will result in system degradation, or ultimately collapse should it pass a limiting threshold.

3. Execution - this provides the capacity to deal with unabsorbed variety (not matched by the system design capacity). Unabsorbed variety is representative of 'system design slop', accentuating inadequacies of the design in relationship to demands of the environment. Execution provides a continual damping of variety and permits the system to maintain performance (dynamic equilibrium) under conditions of varying unabsorbed variety. If execution is not capable of sufficiently matching unabsorbed variety from the system design, the best case is system degradation and the worst case is system collapse.

4. System Development - this represents the continual modification of the system design to more effectively absorb variety stemming from pathologies (unabsorbed variety). The degree to which system redesign maintains residual (unabsorbed) variety below a 'threshold' level ensures continued system viability (continued existence) and is the primary determinant of system performance improvement. This occurs through the continuing maintenance of congruence between the regulatory capacity of the system (variety) in response to variety generated external (or internal) to the system (perturbations that manifest as pathologies representative of unabsorbed (by system design or execution) residual variety.

5. Pathologies - recognizable as aberrations from normal or healthy system conditions. The existence of pathologies represents inadequacies in design, execution, or development for a complex system. Pathologies are the resultant from unabsorbed variety and act to degrade system performance or, in the worst case, cause the system to experience disabling conditions.

Figure 1 shows 'variety' relationships in system design, execution, and development. It is important to note that CSG is an approach that is focused on purposefully dealing with variety. CSG fosters improvement in design and execution through the purposeful pursuit of identification of pathologies (residual unabsorbed variety) and their resolution. There are two significant points of note in this set of variety relationships. First, although simple calculations for variety (as states of the environment) approach infinity rapidly, the actual variety that is projected to the system design is a subset of this total variety, emergent as activities, events, conditions, or trends that occur in the environment of interest for a particular system. Second, the resolution of variety occurs in three system venues, including design (absorption of environmental variety by the system design, producing residual system design variety), execution (absorption of design residual variety beyond the capacity of the system design to address), and development (absorption of execution residual variety resulting from the lack of execution capability to address design residual variety). Pathologies related to variety processing capacity can range across design, execution, and development for a complex system.

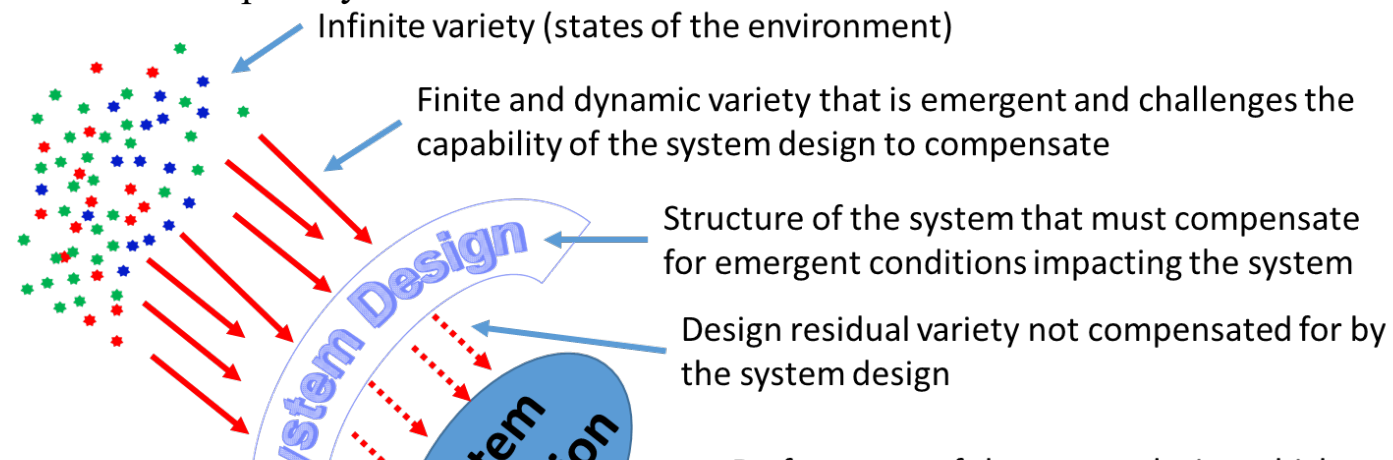


Figure 1. Relationships in the resolution of variety in complex systems.

\section{A Framework for Improving System Performance}

Based on Ashby's Law of Requisite Variety, Complex System Governance, and Pathologies, a framework for improving system performance has been developed. Initial indicators are that this framework provides increased capacity for:

1. Identification of systemic deficiencies (recognized as pathologies) occurring in the design, execution, or development aspects of complex systems.

2. Provision of a baseline set of indicators of the existence of pathologies in a complex system, informing the location (CSG function), criticality (severity of impact on system performance), and essence (the nature of the pathology in relationship to violations of systems principles).

3. More informed system improvement through support for developmental strategies that take into account the relationship of system design, system execution, and system development as an inseparable triad governing system performance and continued viability.

This framework is presented as an initial foray into CSG, utilizing the nature of pathologies that exist in relationship as to how a system goes about disposing of variety. This variety presents challenges to the design, execution, and developmental capacities for a complex system. Ultimately, the intent of this framework is to more precisely convey the new and novel possibilities presented by the emerging CSG field. Figure 2 provides a high level overview of the framework.

There are three interrelated aspects of the framework that are neither mutually exclusive nor independent of one another. These include: 
Discovery - finding the existence of pathologies (unabsorbed variety) across the design, execution, and developmental aspects of complex system performance. These pathologies represent unabsorbed residual variety in the system. The existence, level, and potential impact of pathologies are measurable for a complex system.

Classification - unabsorbed variety (pathologies) in a complex system can be classified within the CSG functions. The classification can locate the source of the pathology (CSG function) as well as the severity of system impact. In addition, the feasibility of addressing a pathology is included in the classification. Feasibility is important to consider, since a system, while recognizing the existence and severity of a pathology, must also consider the ability of the system to address the pathology. Limitations in context, culture, technology, resources, or other local conditions may preclude the resolution of the pathology.

Engagement - discovery and classification of pathologies represent necessary but not sufficient conditions for their resolution. Engagement encompasses the activities, action, decision, and interpretations necessary to develop context and system compatible responses to pathologies. Irrespective of the desire, will, or resources availability to address pathologies, there must be 'requisite feasibility' to effectively engage the pathologies with an acceptable probability of success.

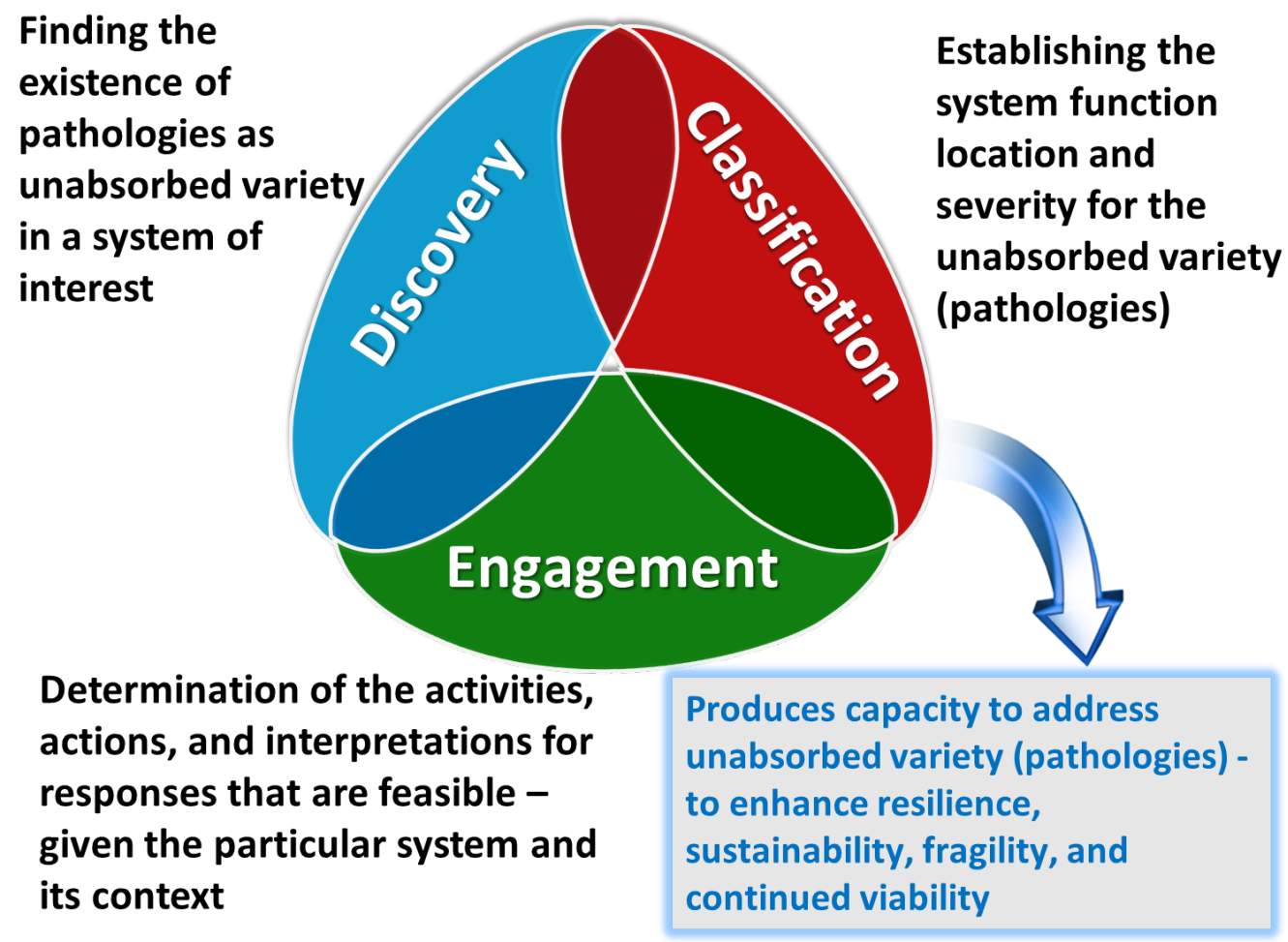

Figure 2. Engaging 'Unabsorbed Variety’ in Complex Systems

\section{Conclusions and Application Guidance}

Initial explorations related to pathologies in CSG have been promising. For instance, Katina's $(2015,2016 \mathrm{a}, 2016 \mathrm{~b})$ works on are especially noteworthy in demonstration of the capabilities for discovery of systems pathologies in CSG. Additionally, CSG is emerging as a new and novel 
perspective to enhance capabilities to more effectively deal with increasingly complex system problems.

In suggesting the implications for the current framework for discovery, classification, and engagement of complex systems we suggest several contributions that can accrue from rigorous application of the framework within the CSG - Pathologies - Requisite Variety triad. Ultimately, this framework is an antecedent to comprehensive complex system development. The evolving CSG field, and the nature of pathologies as a central element in the identification of effectively targeted system development, offer practitioners new and novel insights into the underlying systemic sources of deficiencies in systems. CSG, pathologies, and the framework are not suggested as a panacea for all problems facing complex system and practitioners responsible for their design, execution, and development. Instead, CSG and this framework is advocated as a significant opportunity to provide value in the following four areas:

- Rigorous Guided 'Self-Study' into CSG pathologies can provide significant insights into how the system (program, project, portfolio) actually functions. Although systems function routinely and successfully on a daily basis, as a matter of course practitioners are not particularly skilled, nor do they engage in deep reflection as to why, how, and what they do from a systems point of view. The gains to be made by reflective self-examination, from a systemic point of view, can reveal insights far beyond traditional methods of examination (e.g. Strategic Planning, SWOT analysis, Maturity Modeling, etc.). Thus, practitioners can examine a different level of analysis through 'self-study' and experience insights in a 'safe-to-fail' setting.

- Governance Pathologies Baseline can be established to identify the present state of CSG functions as indicated by the pathologies. The set of 'unique' indicators developed for a specific system of interest can provide a baseline that can be used to longitudinally establish the continuous progression of governance functions improvement. In effect, the degree of improvement stemming from initiatives undertaken to improve CSG pathologies classified as feasible can be established. Therefore, the state and shifts in governance functions can be purposefully and actively planned, deployed, monitored, and adjusted as necessary.

- Enhanced System Awareness is a direct byproduct from the examination of system pathologies. The identification of pathologies related to specific CSG functions, and traceable to underlying systems concepts offers new and novel insights. Thus, the wider consideration of system impediments provided by the identification and classification of pathologies can open the aperture of consideration of aspects for development (engagement) to improve the system.

- Targeted Purposeful Development can provide focus for targeted advancement of the CSG functions through the identification and selection of pathologies for resolution. This accrues through resolution of priority pathologies in performance of system functions necessary to maintain system viability. While all viable (existing) systems perform the CSG functions and have pathologies, it is rare that they are purposefully articulated, examined, or addressed in a comprehensive fashion. Purposeful CSG development to resolve identified pathologies can produce a 'blueprint' against which development can be achieved by design, rather than serendipity. Performance indicators of pathologies as unabsorbed variety exist beyond more 'traditional' measures of system/organizational performance.

Framework application requires a basic level of 'systemic' maturity exist in three primary areas. First, the individual/team planning deployment must be sufficiently sophisticated in the underlying systems-based paradigm to effectively engage the framework. Lacking this immersion can be 
debilitating to the effort and limit potential for 'deep system' development. Second, the support infrastructure will both constrain and enable framework deployment, solution development, and deployment of responsive strategies/actions based on discoveries made during the effort. Overly narrow boundaries for application, leaving support infrastructure unaccounted for, can limit the ability to address 'deep system' deficiencies stemming from support infrastructure. Third, the engaging the framework requires sufficient 'systemic' capacity to embrace the underlying systemic nature of the framework. Lacking this capacity is certain to limit any effort to deploy the framework. Fourth, the 'system of interest' must be explicitly and unambiguously defined. For this definition, the following guidance is provided:

The System of Interest (SOI)includes the collection of entities that produce value (services/products) that is consumed external to the system. Participants appropriate to the exploration of systemic deficiencies should be those who have an active role in design (setting of strategic vision, trajectory, and design for the system [organization]), execution (active in strategic implementation of system [organization] level design), or development (active in assessment and redesign of the system [organization] based on the changing environment). In determination of a System of Interest (SOI) for exploration of a complex system, the following guidance should be helpful in: (1) considerations for what constitutes a SOI, and (2) who are the 'actors' performing critical functions for the SOI. In determining the SOI and actors the following items are provided:

1. Boundary Conditions - the boundary conditions determine what is included and excluded in the SOI. For example, there may be a set of entities that work together to produce a product or service (value) consumed external to the system by consumers/customers who see value in what the SOI is producing. Boundaries for a particular system may include any or all of the following considerations: Entities, geography, time, product, services, customer). What is important is that the system entities and boundary criteria for inclusion/exclusion need to be clear.

2. Entities - who are the major entities (units) that interact to produce the products/services? These form the focus for elements that are: (1) subject to integration and interaction to act as a system and (2) are the set of entities for which 'framework functions' will be explored.

3. Environment - who are the entities that would share a 'common environment' within which the system operates?

4. Responsibilities - Appropriate participants would be those individuals who have responsibilities with respect to Design (establishing how the system [organization] is organized to make decisions, take actions, and make strategic direction determinations), Execution (enacting the strategic design for the system), and Development (planning/implementing initiatives to enhance the system design).

5. Roles -- individuals who play a major role in the system design/development related to: (1) communications - the flow of information and interpretation within the system to support strategic thinking/decision/action, (2) control - design and implementation of higher level constraints to regulate the system, (3) integration - provision for the system to act in unison from a common frame of reference and identity, and (4) coordination - design, implementation, or development of specific vehicles to provide for smooth interactions among entities in support of system level objectives 
6. Functions - individuals who have system level responsibilities related to design, execution, or development of one or more of the following primary governance functions: (1) System Identity (vision, strategic trajectory, strategic performance, primary customer interface/development), (2) System Development (environmental scanning, design for learning, design/execution of environmental scanning), (3) System Operations (performance expectations/measurement, operational direction, performance accountability), or (4) Information and Communications (assessment/design for information exchange, internal/external interfaces and exchange, information infrastructure design for strategic decision support)

Ultimately, the discovery, classification, and engagement of CSG pathologies as unabsorbed variety provides a decidedly different approach to system development. Future development work around this framework will be focused on generation of supporting technologies to allow practitioners to engage CSG through the exploration of pathologies.

\section{References}

Ashby, W. R. (1991). Requisite variety and its implications for the control of complex systems. In Facets of systems science (pp. 405-417). Springer, Boston, MA.

Beer, S. (1978). Platform for change. Chichester, UK: John Wiley.

Boulding, K. E. (1956). General systems theory: The skeleton of science. Management Science, 2(3), 197-208. https://doi.org/10.1287/mnsc.2.3.197

Clemson, B. (1984). Cybernetics: A new management tool. Tunbridge Wells, Kent, UK: Abacus Press. Hammond, D. (2002). Exploring the genealogy of systems thinking. Systems Research and Behavioral Science, 19(5), 429-439. https://doi.org/10.1002/sres.499

Katina, P. F. (2015), "Emerging systems theory-based pathologies for governance of complex systems", International Journal of System of Systems Engineering, Vol. 6 No. 1/2, pp. $144-159$.

Katina, P. F. (2015a). Emerging systems theory-based pathologies for governance of complex systems. International Journal of System of Systems Engineering, 6(1/2), 144-159.

https://doi.org/10.1504/IJSSE.2015.068806

Katina, P. F. (2015b). Systems theory-based construct for identifying metasystem pathologies for complex system governance (Ph.D.). Old Dominion University, United States -- Virginia. Retrieved from http://search.proquest.com.proxy.lib.odu.edu/docview/1717329758/abstract/29A520C8C0A 744A2PQ/2

Katina, P. F. (2016a). Metasystem pathologies (M-Path) method: phases and procedures. Journal of Management Development, 35(10), 1287-1301.

Katina, P. F. (2016a). Metasystem pathologies (M-Path) method: Phases and procedures. Journal of Management Development, 35(10), 1287-1301.

https://doi.org/10.1108/JMD-02-2016-0024

Katina, P. F. (2016b). Systems theory as a foundation for discovery of pathologies for complex system problem formulation. In A. J. Masys (Ed.), Applications of Systems Thinking and Soft Operations Research in Managing Complexity (pp. 227-267). Geneva, Switzerland: Springer International Publishing.

Katina, P. F. (2016b). Systems theory as a foundation for discovery of pathologies for complex system problem formulation. In A. J. Masys (Ed.), Applications of Systems Thinking and Soft Operations Research in Managing Complexity (pp. 227-267). Geneva, Switzerland: Springer 
International Publishing. Retrieved from

http://link.springer.com/chapter/10.1007/978-3-319-21106-0_11

Katina, P. F., \& Keating, C. B. (2014). Metasystem pathologies: Towards a systems-based construct for complex system deficiencies. In S. Long, E.-H. Ng, \& C. Downing (Eds.), Proceedings of the American Society for Engineering Management 2014 International Annual Conference. Virginia Beach, VA: American Society for Engineering Management.

Katina, P. F., \& Keating, C. B. (2016). Metasystem Pathologies: Towards discovering of impediments to system performance. In H. Yang, Z. Kong, \& M. D. Sarder (Eds.), Proceedings of the 2016 Industrial and Systems Engineering Research Conference. Anaheim, CA.

Keating, \& Bradley, J. M. 2015. Complex system governance reference model. International Journal of System of Systems Engineering, 6(1), 33-52.

Keating, C. B., \& Bradley, J. M. (2015). Complex system governance reference model. International Journal of System of Systems Engineering, 6(1), 33-52.

Keating, C. B., \& Katina, P. F. (2012). Prevalence of pathologies in systems of systems. International Journal of System of Systems Engineering, 3(3-4), 243-267.

Keating, C. B., Bradley, J. M., Katina, P. F., Jaradat, R.M. (2017b). A Systems Theoretic-Based Framework to Discover Pathologies in Acquisition System Governance. In Fourteenth Annual Acquisition Research Symposium. Naval Postgraduate School, pp. 352-376.

Adams, K. M., Hester, P. T., Bradley, J. M., Meyers, T. J., \& Keating, C. B. (2014). Systems theory as the foundation for understanding systems. Systems Engineering, 17(1), 112-123.

Keating, C.B. 2014. Governance Implications for Meeting Challenges in the System of Systems Engineering Field. Paper presented at the IEEE System of Systems Engineering Conference, Adelaide, SA.

Keating, Katina, P.F., \& Bradley, J.M. 2015. Challenges for Developing Complex System Governance. Paper presented at the Proceedings of the 2015 Industrial and Systems Engineering Research Conference.

Kramer, N. J., \& De Smit, J. (1977). Systems thinking: Concepts and notions. Springer Science \& Business Media.

Skyttner, L. 2005. General systems theory: Problems, perspectives, practice (2nd ed.). Singapore, : World Scientific Publishing Co. Pte. Ltd.

Troncale, L. (1977). Linkage propositions between fifty principal systems concepts. In G. J. Klir (Ed.), Applied general systems research: Recent development and trends (pp. 29-52). New York, NY: Plenum Press.

van Gigch, J. P. (1974). Applied general systems theory (2nd ed.). New York: NY: Harper and Row.

von Bertalanffy, L. (1950). The theory of open systems in physics and biology. Science, 111(2872), 23-29.

von Bertalanffy, L. (1968). General system theory: Foundations, developments, applications. New York, NY: George Braziller.

Whitney, K., Bradley, J.M., Baugh, D.E., \& Chesterman, C. W., Jr. 2015. Systems theory as a foundation for governance of complex systems. International Journal of System of Systems Engineering, 6(1), 15-32. 